\title{
SINTESIS NANOSILIKA DARI ABU KETEL INDUSTRI GULA DENGAN METODE ULTRASONIKASI DAN PENAMBAHAN SURFAKTAN
}

\section{SYNTHESIS OF NANOSILICA FROM BOILER ASH OF SUGAR CANE INDUSTRY WITH ULTRASONICATION METHOD AND ADDITION OF SURFACTANT}

\author{
Andes Ismayana ${ }^{1)}$, Akhiruddin Maddu ${ }^{2}$, Illah Saillah ${ }^{1}$, Ersyad Mafquh ${ }^{1)}$, Nastiti Siswi Indrasti ${ }^{11^{*}}$ \\ ${ }^{1)}$ Departemen Teknologi Industri Pertanian, Fakultas Teknologi Pertanian, Institut Pertanian Bogor \\ Kampus IPB Dramaga Bogor PO Box 220, 16680 \\ Email: nastiti.indrasti@gmail.com \\ ${ }^{2)}$ Program Studi Fisika, Fakultas Matemamatika dan Ilmu Pengetahuan Alam, Institut Pertanian Bogor
}

Makalah: Diterima 2 Desember 2016; Diperbaiki 20 Juli 2017; Disetujui 2 Agustus 2017

\begin{abstract}
Boiler ash from sugar industry contains silica compounds which could be synthesized into nanosilica by ultrasonication method. The addition of surfactants in this synthesis method can affect the characteristics of nanosilica. This study aims to synthesize nanosilica with ultrasonication method and determine the effect of surfactants on characteristics of nanosilica generated. This research was divided into three stages: (1) boiler ash preparation to furnace ash, (2) silica extraction from furnace ash, and (3) synthesis of nanosilica using ultrasonication method with surfactant addition: PEG 6000 1:5, CMC 2.5\% (b/b), CMC 5\% (b/b), CMC 10\% $(b / b)$, and Tween $803 \%(b / v)$. Silica content in boiler ash and furnace ash was $49.69 \%$ and $78.75 \%$, respectively. The nanosilics produced using the ultrasonication method had the uniform size (PDI) of 0.638, and with the addition of surfactant might increase the uniformity of the particle (PDI) to 0.045 and 0.047 on the usage of CMC 5 and $2.5 \%$. The addition of surfactant also increased the crystallinity degree from $76.96 \%$ at no surfactant to $84.04 \%$ with 10\% CMC surfactant added. The crystalline size of the silica nanoparticles also became smaller with the addition of 10\% CMC of $37.69 \mathrm{~nm}$ from $41.40 \mathrm{~nm}$ crystal size without the addition of surfactant. The addition of an enlarged CMC concentration would increase the degree of crystallinity and decrease the crystal size of the nanosilica particles.
\end{abstract}

Keywords : boiler ash, nanosilica, ultrasonication, surfactant, degree of crystallinity

\section{ABSTRAK}

Abu ketel industri gula memiliki kandungan silika yang dapat disintesis menjadi nanosilika dengan metode ultrasonikasi. Penambahan surfaktan pada sintesis nanosilika dengan metode ulttrasonikasi dapat mempengaruhi karakteristik nanosilika yang dihasilkan. Penelitian ini bertujuan untuk melakukan sintesis nanosilika dengan metode ultrasonikasi dan mengetahui pengaruh penambahan surfaktan terhadap karakteristik nanosilika yang dihasilkan. Penelitian ini dibagi menjadi tiga tahap, yaitu (1) preparasi abu ketel menjadi abu tanur, (2) ekstraksi silika dari abu tanur,dan (3) sintesis nanosilika menggunakan metode ultrasonikasi dengan penambahan surfaktan PEG 6000 1:5, CMC 2,5\% (b/b), CMC 5\% (b/b), CMC 10\%, (b/b) dan Tween $803 \%$ (b/v). Kadar silika dalam abu ketel dan abu tanursecara berturut-turut adalah 49,69\% dan 78,75\%. Nanosilika yang dihasilkan menggunakan metode ultrasonikasi memiliki ukuran keseragaman (PDI) sebesar 0,638, dan dengan penambahan surfaktan dapat meningkatkan nilai keseragaman partikel sampai 0,045 dan 0,047 pada penggunaan CMC 5 dan 2,5\%. Penambahan surfaktan juga meningkatkan derajat kristalinitas dari 76,96\% pada saat tanpa penambahan surfaktan sampai mencapai 84,04\% dengan penambahan surfaktan CMC $10 \%$. Ukuran kristal partikel nanosilika juga menjadi lebih kecil dengan penambahan CMC 10\% yaitu sebesar 37,69 nm dari ukuran kristal 41,40 nm tanpa penambahan surfaktan. Penambahan konsentrasi CMC yang semakin tinggi akan meningkatkan derajat kristalinitas dan menurunkan ukuran kristal partikel nanosilika.

Kata kunci : abu ketel, nanosilika, ultrasonikasi, surfaktan, derajat kristalinitas

\section{PENDAHULUAN}

Silika adalah suatu polimer anorganik yang tersusun atas unsur silikon dan oksigen dengan rumus kimia $\mathrm{SiO}_{2}$. Silika merupakan suatu senyawa anorganik yang sering digunakan dalam kehidupan manusia karena memiliki banyak potensi pemanfaatan yang luas, seperti insulator termal, penyangga katalis, adsorben, penghantar obat, bahan pengisi pada gelas, kaca, dan bahan baku pembuatan sel surya (Gurav et al., 2009). Silika dapat disintesis dari berbagai sumber di alam, khususnya dari pertanian. Beberapa sumber silika dari kegiatan pertanian antara lain, seperti abu sekam padi (Thuadaij dan Nuntiya, 2008; Suka et al.,2008), abu cangkang sawit (Pausa et al.,2015), abu boiler dari industri pulp dan kertas (Purwati et al.,2007), dan abu ketel dari industri gula (Affandi et al.,2009). 
Abu ketel atau abu pembakaran bagas pada industri gula merupakan salah satu sumber potensial mineral silika. Affandi et al. (2009) menegaskan bahwa mineral silika merupakan unsur yang dominan pada abu ketel hasil pembakaran bagas pada industri gula. Abu ketel adalah hasil perubahan secara fisik dari pembakaran bagas murni. Bagas merupakan zat padat dari tebu yang diperoleh sebagai hasil samping proses pengolahan tebu pada industri gula. Bagas umumnya dimanfaatkan sebagai sumber energi utama untuk menghasilkan uap air. Hasil dari pembakaran bagas tersebut berupa abu pembakaran atau biasa disebut abu ketel (Affandi et al.,2009). Potensi abu ketel ini sangat besar. Berdasarkan laporan sebuah pabrik gula pada tahun 2010 menunjukkan jumlah blotong dapat mencapai $3,8 \%$ dari total tebu yang digiling atau sekitar $10 \%$ dari jumlah bagas atau dapat mencapai 4,5 juta ton per tahun. Sedangkan potensi abu ketel yang terbentuk berdasarkan jumlah perolehannya sekitar 1,5-2\%, maka didapat sekitar 1,7-2,3 juta ton per tahun (Ismayana, 2014). Pemanfaatan abu ketel selama ini belum dilakukan secara optimal. Beberapa penelitian menyebutkan bahwa limbah abu ketel dimanfaatkan untuk pembuatan kompos bersama dengan blotong (Misran, 2005). Setyawan et al. (2007) memanfaatkan abu ketel untuk bahan dasar silika gel.

Pemanfaatan silika dapat diperluas dengan meningkatkan karakteristiknya. Salah satu cara untuk meningkatkannya adalah dengan melakukan sintesis silika dalam ukuran nano. Nanopartikel adalah partikel padat dengan ukuran sekitar 10-1000 nm (Tiyaboonchai, 2003; Mohanraj dan Chen, 2006). Nanopartikel memiliki sifat yang khas seperti luas permukaan yang besar, jumlah atom dipermukaan yang besar, energi permukaan dan tegangan permukaan yang tinggi sehingga banyak diminati karena memiliki ukuran partikel yang sangat kecil (Thassu et al.,2007).

Salah satu metode pembentukan nano partikel adalah dengan menggunakan metode ultrasonikasi. Metode tersebut memanfaatkan efek kavitasi yang dihasilkan dari gelombang ultrasonikasi yang merambat dalam medium cair (Lidiniyah, 2011; Safitri, 2012; Kurniawan, 2013). Menurut Siswanto et al.(2012), metode ultrasonikasi tersebut dapat menghasilkan partikel dengan kristalinitas tinggi. Hal ini diharapkan dapat mengubah karakter partikel silika dari abu bagas yang memiliki fase amorf (Affandi et al.,2009). Kelebihan dari metode ini dibandingkan metode yang umumnya sudah digunakan, seperti presipitasi, adalah kemampuan dalam merekayasa karakteristik nanosilika menjadi kristal dan waktu sintesis yang relatif lebih cepat (Safitri, 2012; Kurniawan, 2013). Ultrasonikasi pada cairan memiliki berbagai faktor yang dapat berpengaruh, seperti frekuensi, tekanan, viskositas, dan konsentrasi (Safitiri, 2012). Pada penelitian sebelumnya yang telah dilakukan
Ismayana (2014), peluang terbentuknya partikel nanosilika dilakukan dengan menggunakan metode ultrasonikasi dengan lama waktu 2 jam, frekuensi $20 \mathrm{kHz}$, dan amplitudo 40\%, menunjukkan peningkatan nilai derajat kristalinitas silika dari $76,43 \%$ menjadi nanosilica $83,66 \%$, dan dibandingkan dengan metode presipitasi yang menghasikan nanosilika dengan derajat kritalinitas sebesar $54,57 \%$.

Kendala yang umumnya terjadi pada sintesis nanopartikel adalah ketidakseragaman ukuran partikel dan cepatnya proses aglomerasi dari partikel tersebut. Oleh karena itu, perlu adanya perlakuan khusus pada proses sintesis nanopartikel, salah satunya yaitu dengan menambahkan surfaktan. Surfaktan dapat menurunkan tegangan permukaan suatu cairan saat terjadi proses kavitasi sehingga mampu mendispersikan suatu larutan secara sempurna dan menstabilkan partikel sehingga tidak terjadi aglomerasi (Lidiniyah, 2011), sehingga dapat terjadi keseragaman partikel. Adapun surfaktan yang digunakan pada penelitian ini ada 3 jenis, yaitu PEG 6000, CMC (carboximethyl cellulose), dan Tween 80. PEG 6000 merupakan pembawa inert yang mudah larut air. Sifat kristalin PEG 6000 yang dominan dengan membentuk habit sferulit yang sangat teratur. Komponen molekul-molekul dalam kisi kristal PEG 6000 (suhu lebur yang lebih rendah) secara dinamis melakukan pertukaran tempat.PEG 6000 juga merupakan polimer kristalin dengan tingkat kesimetrian yang tinggi (Gao, 1993). CMC (carboxymethylcellulose) pada umumnya digunakan sebagai stabilizer, pengental, dan emulsifier (Lestari et al.,2014). Tween 80 digunakan sebagai agen pengemulsi (1-15\% konsentrasi), agen pelarut (1$10 \%$ konsentrasi), agen wetting, dispersi/suspensi (0,1-3\% konsentrasi) dan sebagai surfaktan nonionik (Tarirai, 2005).

Penelitian ini bertujuan untuk mensintesis nanosilika menggunakan metode ultrasonikasi dengan penambahan surfaktan PEG 6000, CMC (carboxymethyl cellulose)dan Tween 80, mengetahui pengaruh penambahan surfaktan terhadap nanosilika yang dihasilkan.

\section{BAHAN DAN METODE}

Penelitian ini dilakukan dalam beberapa tahapan, yaitu preparasi abu ketel, ekstraksi silika dari abu tanur, sintesis nanosilika menggunakan metode ultrasonikasi, dan karakterisasi abu serta nanosilika yang dihasilkan. Bahan yang digunakan dalam penelitian ini adalah abu ketel yang diperoleh dari Pabrik Gula Gunung Madu Plantation (GMP), PEG 6000, CMC (carboximethyl cellulose), dan Tween 80.

Alat yang digunakan dalam penelitian ini adalah tanur, peralatan refluks, dan ultrasonikator. Peralatan analisis yang digunakan meliputi PSA (particle size analyzer) Vasco, XRF (X-Ray 
florescence) ARL OPTX-2050, XRD (X-Ray diffractometer) GBC Emma, dan SEM (scanning electron microscope).

\section{Preparasi Abu Ketel}

Preparasi dilakukan untuk membersihkan abu ketel dari kotoran dan bahan asing. Abu ketel dari industri gula dicuci menggunakan aquades. Kemudian dikeringkan dalam oven dengan suhu $105^{\circ} \mathrm{C}$ selama 5 jam. Setelah itu, abu ketel disaring menggunakan saringan kasar dan diabukan pada suhu $700^{\circ} \mathrm{C}$ selama 6 jam menggunakan tanur (Thuadaij dan Nuntiya, 2008). Setelah diperoleh abu tanur, kemudian dilakukan karakterisasi terhadap abu tanur dan juga abu ketel sebelum dipanaskan.

\section{Ekstraksi Silika dari Abu Tanur}

Pada tahapan ini, basis yang digunakan adalah abu tanur sebanyak $10 \mathrm{~g}$. Abu tanur direfluks dalam $80 \mathrm{~mL} \mathrm{NaOH} 3 \mathrm{~N}$ selama 3 jam. Larutan disaring dengan kertas saring dan residu dicuci menggunakan $20 \mathrm{~mL}$ aquades mendidih. Filtrat didinginkan sesuai suhu ruang. Setelah dingin, filtrat ditambahkan $\mathrm{H}_{2} \mathrm{SO}_{4} 5 \mathrm{~N}$ hingga $\mathrm{pH}$ menjadi 2 dilanjutkan penambahkan $\mathrm{NH}_{4} \mathrm{OH}$ 2,5 $\mathrm{N}$ hingga $\mathrm{pH}$ menjadi 8,5. Proses ini dilakukan diatas peralatan magnetic stirrer. Larutan Filtrat tersebut dibiarkan dalam suhu ruang selama 3,5 jam, dan dilanjutkan dengan pengeringkan pada suhu $105^{\circ} \mathrm{C}$ selama 12 jam (Thuadaij dan Nuntiya, 2008; Ismayana, 2014).

\section{Sintesis Nanosilika denganMetodeUltrasonikasi}

Tahap selanjutnya adalah pembuatan nanosilika dengan metode ultrasonikasi. Metode ultrasonikasi dilakukan dengan menggunakan peralatan ultrasonikasi dengan panjang gelombang $20 \mathrm{kHz}$, daya 130 watt, amplitudo $40 \%$ selama 120menit. Silika yang dihasilkan sebelumya didispersikan terlebih dahulu dengan surfaktan. Surfaktan yang digunakan pada penelitian ini adalah PEG 6000 dengan rasio 1:5 (Delmifiana dan Astuti, 2013), CMC dengan konsentrasi 2,5\%, 5\%, dan $10 \%$ (b/b), dan Tween $803 \%$ (Safitri, 2012).

Cara penambahan tiap jenis surfaktan tidak sama. Pada jenis surfaktan yang bersifat mudah larut dalam air di suhu ruang, seperti CMC dan Tween 80, dilarutkan terlebih dahulu dalam air dengan perbandingan 1:8 (b/v). Setelah terbentuk larutan, kemudian silika dilarutkan ke dalam larutan. Sementara itu, pada jenis surfaktan yang bersifat semi kristalin dan memiliki titik leleh yang tinggi, seperti PEG 6000, perlu adanya perlakuan pemanasan di suhu titik lelehnya. Setelah PEG 6000 mencair, kemudian silika dilarutkan dalam PEG cair tersebut dengan perbandingan 1:5. Pelarutan dibantu dengan menggunakan magnetic stirrer selama 15 menit agar silika dapat terdispersi secara baik dalam larutan tersebut.

Larutan selanjutnya dilakukan proses ultrasonikasi menggunakan ultrasonic bath untuk memecah partikel silika menjadi partikel nano. Larutan hasil ultrasonikasi dikeringkan dengan oven $105^{\circ} \mathrm{C}$ selama 24 jam, kemudian dilakukan proses kalsinasi dalam tanur pada suhu $750^{\circ} \mathrm{C}$ (Thuadaij dan Nuntiya, 2008; Delfimiana dan Astuti, 2013).

\section{Metode Analisis Parameter}

Analisis menggunakan XRF (X-Ray fluorescence) dengan menimbang sebanyak $5 \mathrm{~g}$ abu ketel atau abu tanur, dipindai, dan dikalibrasikan sesuai energi dan intensitasnya dengan detektor Si (Li) (Sintilation).

Analisis ukuran partikel dilakukan dengan menggunakan peralatan PSA (particle size analyzer), dengan menimbangsebanyak 0,002 $\mathrm{g}$ nanosilika dan didispersikan dalam $100 \mathrm{~mL}$ akuades. Larutan diaduk menggunakan magnetic stirrer selama 20 menit. Pemindaian partikel nanosilika dilakukan selama 2-10 menit.

Analisis difraktogram dengan peralatan XRD ( $X$-Ray diffraction) dioperasikan menggunakan radiasi $\mathrm{Cu}-\mathrm{K} \alpha$ dengan panjang gelombang $(\lambda)$ 1.54056 Å. Difraktogram dipindai mulai $10^{\circ}$ sampai $80^{\circ}$ (20) dengan laju pemindaian $3^{\circ}$ per menit. Perhitungan derajat kristalinitas menggunakan software PowderX dan ukuran kristal menggunakan persamaan Scherrer.

Analisis gugus fungsi menggunakan FTIR (Fourier Transform Infrared) dilakukan dengan menimbang sebanyak $2 \mathrm{mg}$ sampel nanosilika,dan ditambahkan $200 \mathrm{mg} \mathrm{KBr}$ untuk dibentuk menjadi pellet untuk selanjutnya dipindai menggunakan FTIR.

\section{HASIL DAN PEMBAHASAN}

\section{Karakteristik Abu}

Hasil karakterisasi abu ketel diketahui bahwa kandungan silika $\mathrm{SiO}_{2}$ mencapai 49,69\% dan masih terdapat banyak bahan pengotor lainnya, seperti $\mathrm{Al}_{2} \mathrm{O}_{3}, \mathrm{~K}_{2} \mathrm{O}, \mathrm{P}_{2} \mathrm{O}_{5}, \mathrm{Na}_{2} \mathrm{O}, \mathrm{CaO}, \mathrm{MgO}, \mathrm{Fe}_{2} \mathrm{O}_{3}$, $\mathrm{SO}_{3}$, dan $\mathrm{TiO}_{2}$. Setelah dilakukan pembakaran abu ketel melalui pemanasan pada suhu $700^{\circ} \mathrm{C}$ selama 6 jam, dan menjadi abu tanur), kadar silika pada abu tanur menjadi $78,75 \%$. Adanya pemanasan tersebut menyebabkan senyawa pengotor lainnya ikut tereduksi dan kadarnya menjadi lebih kecil, bahkan ada diantaranya yang tidak terdeteksi lagi, seperti senyawa $\mathrm{P}_{2} \mathrm{O}_{5}$ dan $\mathrm{SO}_{3}$. Hal ini terjadi karena titik lebur dari senyawa-senyawa tersebut berada dibawah suhu $700^{\circ} \mathrm{C}$. Silika memiliki titik lebur sekitar 1600 $1700^{\circ} \mathrm{C}$ sehingga tidak mengalami penurunan jumlah akibat pengabuan suhu $700^{\circ} \mathrm{C}$.

Kandungan silika pada abu tanur tersebut lebih tinggi dari kandungan silika pada abu sekam hasil pemanasan bagas pada suhu $350^{\circ} \mathrm{C}$ yang dilanjutkan pengarangan pada suhu $500-800^{\circ} \mathrm{C}$ yang dilakukan oleh Hanafi dan Nandang (2010) yaitu sebesar 64,65\%. Penelitian Affandi et al.(2009) menyebutkan bahwa senyawa silica dalam abu ketel 
adalah sebesar 50,36\%. Hasil karakterisasi abu ketel dan abu tanur menggunakan XRF (X-Ray fluorescence) disajikan pada Tabel 1.

Tabel 1. Kandungan senyawa abu ketel dan abu tanur

\begin{tabular}{llcc}
\hline No & Senyawa & $\begin{array}{c}\text { Abu Ketel } \\
(\%)\end{array}$ & $\begin{array}{c}\text { Abu Tanur } \\
(\%)\end{array}$ \\
\hline 1 & $\mathrm{SiO}_{2}$ & 49,69 & 78,75 \\
2 & $\mathrm{Al}_{2} \mathrm{O}_{3}$ & 11,24 & 10,36 \\
3 & $\mathrm{~K}_{2} \mathrm{O}$ & 8,76 & 1,80 \\
4 & $\mathrm{P}_{2} \mathrm{O}_{5}$ & 8,14 & 0,00 \\
5 & $\mathrm{Na}_{2} \mathrm{O}$ & 7,00 & 0,21 \\
6 & $\mathrm{CaO}$ & 4,95 & 0,89 \\
7 & $\mathrm{MgO}$ & 3,59 & 1,06 \\
8 & $\mathrm{Fe}_{2} \mathrm{O}_{3}$ & 3,23 & 5,37 \\
9 & $\mathrm{SO}_{3}$ & 1,63 & 0,00 \\
10 & $\mathrm{TiO}_{2}$ & 0,79 & 0,62 \\
\hline
\end{tabular}

\section{Analisis Ukuran Partikel}

Hasil ukuran nanopartikel silika yang dihasilkan dapat dilihat pada Tabel 2. Rata-rata ukuran partikel pada sampel tanpa template yang dihasilkan paling kecil dengan ukuran 203,94 nm dengan PDI 0,638. Hal ini menunjukkan keseragaman ukuran yang dihasilkan sangat kecil karena peluang untuk terjadinya aglomerasi masih tinggi dengan tanpa penambahan surfaktan. Berbeda dengan sampel yang menggunakan surfaktan, keseragaman ukuran yang ditunjukkan dengan nilai PDI relatif lebih kecil karena penambahan surfaktan meminimumkan terjadinya proses aglomerasi. Sifat hidrofob dan hidrofil yang dimiliki oleh surfaktan tersebut akan mempertahankan ukuran partikel akhir yang terbentuk akibat proses kavitasi sehingga ukuran partikel yang dihasilkan pada sampel PEG 6000, CMC, dan Tween 80 lebih stabil.

Distribusi ukuran yang paling seragam adalah sampel C3 yang menggunakan surfaktan CMC kadar 2,5\% dengan ukuran 408,76 nm dan particle dispertion index (PDI) 0,047. Pada nanosilika yang dihasilkan dengan penambahan CMC 10\% menunjukkan keseragaman ukuran yang kecil dengan PDI 0,496. Hal ini disebabkan dari viskositas medium yang berbeda. Semakin banyak penambahan CMC yang digunakan akan menimbulkan viskositas medium yang semakin tinggi. Menurut Lidiniyah (2011), nilai viskositas berbanding terbalik dengan energi yang dihasilkan dari proses ultrasonikasi. Formula yang memiliki viskositas yang rendah memiliki energi yang tinggi. Rendahnya nilai viskositas akan mempermudah terjadinya gelembung kavitasi.

Adanya perbedaan energi dalam mengaktifkan gelembung kativasi ini yang memungkinkan distribusi partikel pada viskositas yang lebih rendah akan lebih seragam dibandingkan dengan viskositas yang lebih tinggi. Namun demikian pengaruh aglomerasi juga memberikan pengaruh terhadap keseragaman partikel yang dihasilkan, seperti yang terlihat pada larutan yang tidak menggunakan template, walaupun viskositasnya rendah, keseragaman partikelnya kurang optimal karena ada partikel-partikel yang dapat bergabung kembali.

Tabel 2. Ukuran nanopartikel silika

\begin{tabular}{cccc}
\hline Sampel & Range $(\mathbf{n m})$ & $\begin{array}{c}\text { Rata-rata } \\
(\mathbf{n m})\end{array}$ & PDI \\
\hline Tanpa Template & $22,39-3716,34$ & 203,94 & 0,638 \\
PEG 6000 & $44,68-1698,69$ & 259,99 & 0,244 \\
CMC 10\% & $35,39-3891,48$ & 294,73 & 0,496 \\
CMC 5\% & $213,85-1023,56$ & 462,89 & 0,045 \\
CMC 2.5\% & $186,26-933,50$ & 408,76 & 0,047 \\
Tween 80 3\% & $48,79-2239,31$ & 300,02 & 0,320 \\
\hline
\end{tabular}

\section{Analisis Difraktogram XRD}

Proses ultrasonikasi pada partikel silika dalam mensintesa nanosilika memberikan perubahan fase silika yang mulanya amorf menjadi lebih kristal. Hal ini terjadi karena ultrasonikasi hanya memotong kristal yang besar tanpa memecahkan struktur ikatan kimianya. Proses sonikasi menghasilkan susunan partikel silika menjadi lebih kristal, karena proses ini hanya memotong kristal yang besar tanpa memecahkan struktur ikatan kimianya. Proses sonikasi juga akan menimbulkan panas yang mendorong susunan kristal menjadi lebih teratur. Sembiring dan Karo-Karo (2007) menyebutkan adanya transformasi amorf ke kristal dengan peningkatan suhu dari 750 ke $1050^{\circ} \mathrm{C}$ dengan membentuk fasa kristal cristobalite dan trydimit yang menunjukkan peningkatan kestabilan termal dari silika. Awizar et al. (2013) menunjukkan perubahan bentuk amorf silika pada pemanasan $600^{\circ} \mathrm{C}$ menjadi semi kristalin pada suhu $700^{\circ} \mathrm{C}$ dan kristalin pada suhu $900^{\circ} \mathrm{C}$.

Derajat kristalinitas partikel nanosilika yang dihasilkan (Tabel 3) menunjukkan bahwa nanosilika yang disintesis menggunakan surfaktan memiliki derajat kristalinitas yang lebih tinggi daripada nanosilika tanpa surfaktan. Pada penelitian penambahan surfaktan CTA terhadap ZnO, Greetha dan Thilagavanthi (2010) menunjukkan peran surfaktan kationik berfungsi sebagai agen yang mengarahkan pembentukkan struktur kristal.

Tabel 3. Derajat kristalinitas nanosilika

\begin{tabular}{lcc}
\hline Sampel & $\begin{array}{c}\text { Derajat } \\
\text { Kristalinitas } \\
(\%)\end{array}$ & $\begin{array}{c}\text { Rataan } \\
\text { Ukuran } \\
\text { Kristal (nm) }\end{array}$ \\
\hline Tanpa Template & 76,96 & 41,40 \\
PEG 6000 & 78,58 & 38,84 \\
CMC 10\% & 84,04 & 37,69 \\
CMC 5\% & 82,07 & 39,29 \\
CMC 2,5\% & 78,45 & 39,53 \\
Tween 80 3\% & 79,59 & 41,48 \\
\hline
\end{tabular}

Hal ini ditekankan juga oleh Abdullah et al. (2008) bahwa surfaktan tersebut tidak hanya digunakan untuk pertumbuhan kristal, tetapi juga 
untuk mencegah terjadinya pembentukkan agregat pada kristal sehingga melindungi permukaan tersebut dari atom prekusor lainya. Dengan adanya perlindungan ini pertumbuhan kristal menjadi lebih baik dan mengakibatkan derajat kristalinitas semakin tinggi. Adanya perlindungan pertumbuhan kristal oleh surfaktan ditunjukkan juga dengan perbedaan penambahan surfaktan CMC pada konsentrasi yang berbeda.

Pada nanosilika yang disintesis menggunakan CMC, hasilnya menunjukkan adanya perbedaan derajat kristalinitas dengan besarnya konsentrasi CMC yang diberikan. Oleh karena itu, dapat diketahui bahwa semakin banyak surfaktan yang ditambahkan, maka akan meningkat pula derajat kristalinitas dari kristal nanosilika yang dihasilkan. Dengan adanya penambahan surfaktan yang lebih tinggi, maka pertumbuhan kristal akan lebih terjaga, sehingga derajat kristalinitas dapat menjadi lebih tinggi.

Penentuan ukuran kristal dilakukan dengan menggunakan persamaan Scherrer :

$$
D=\frac{\mathrm{k} \lambda}{\mathrm{B} \cos \theta}
$$

Dimana $\mathrm{k}$ merupakan konstanta scherrer $(0,9), \lambda$ adalah panjang gelombang $\mathrm{Cu}(0,154 \mathrm{~nm}), \mathrm{B}$ merupakan lebar kurva. Hasil rataan ukuran kristal yang didapatkan terdapat dalam kisaran 37-41 nm.
Adanya penambahan surfaktan akan menurunkan rataan ukuran kristal nanosilika. Penelitian Fahyuan et al. (2013) menjelaskan bahwa penurunan ukuran kristal disebabkan karena dengan penambahan surfaktan (CTAB), terdapat efek tekanan untuk memadatkan kristal lebih tinggi, akibatnya jarak antar bidang menjadi lebih dekat dan ukuran kristal menjadi lebih kecil, sehingga dengan penambahan surfaktan dihasilkan ukuran kristal yang lebih kecil dibandingkan dengan sampel tanpa penambahan surfaktan, walaupun pada konsentrasi tertentu akan kembali meningkatkan ukuran kristal yang disebabkan proses emulsi balikan (reverse emulsion).

Pola difraksi pada Gambar 1 menunjukkan perbedaan yang jelas pada tinggi intensitas antara nanosilika tanpa template dan nanosilika dengan penambahan surfaktan. Nanosilika tanpa template memiliki intensitas paling rendah daripada nanosilika yang ditambahkan surfaktan, baik surfaktan jenis PEG, CMC, maupun tween 80.

Perbedaan intensitas yang terjadi menjadi salah satu indikator yang menunjukkan tinggi atau rendahnya derajat kristalinitas nanosilika yang dihasilkan. Semakin tinggi intensitas yang ditunjukkan dalam pola difraksi, maka semakin tinggi pula derajat kristalinitas dari nanosilika. Jika intensitas pada pola difraksi rendah, maka derajat kristalinitas nanosilika cenderung lebih rendah pula.
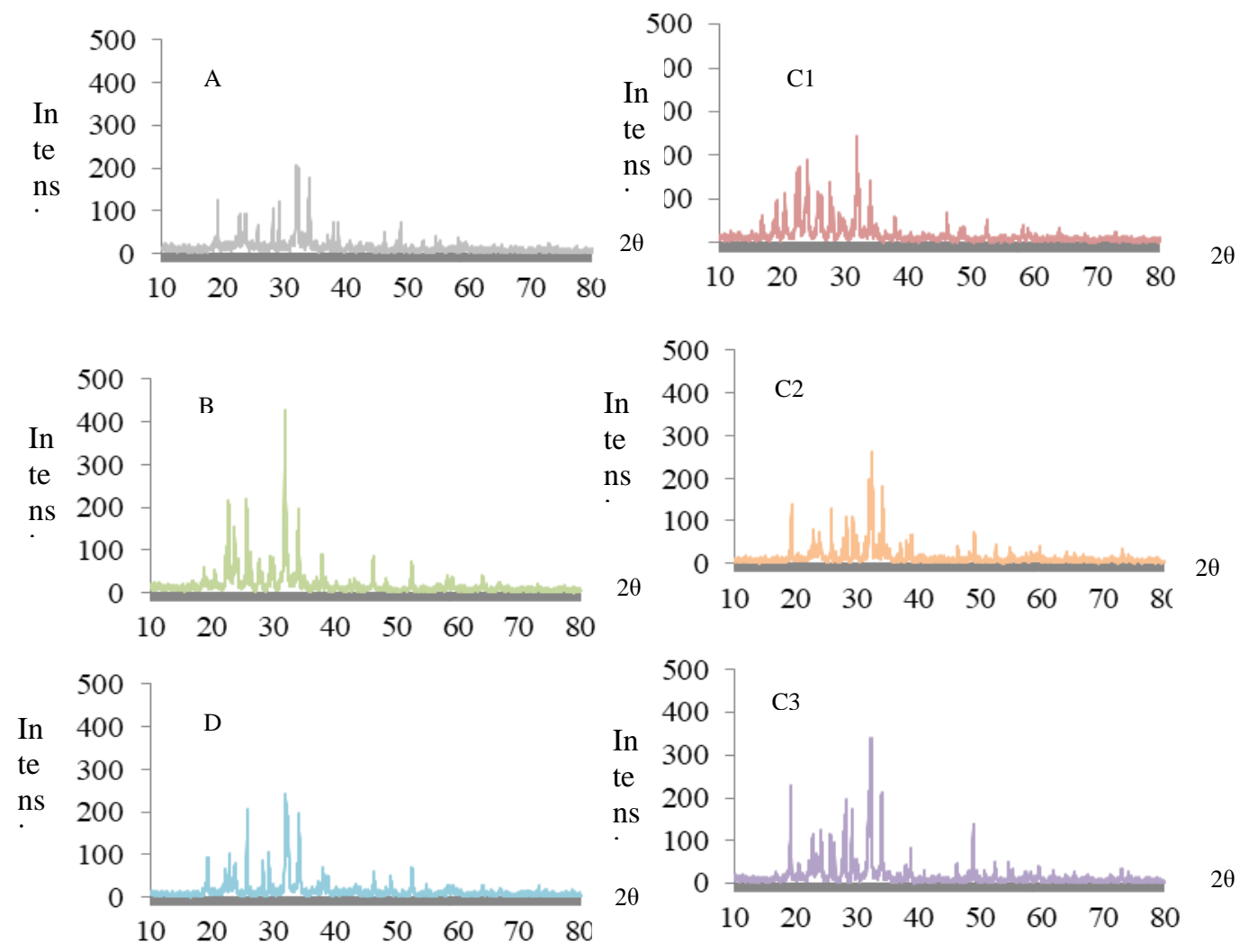

Gambar 1.Pola difraksi nanosilika (A) tanpa template, (B) PEG 6000, (C1) CMC 10\%, (C2) CMC 5\%, (C3) CMC 2,5\%, dan (D) tween 80 . 


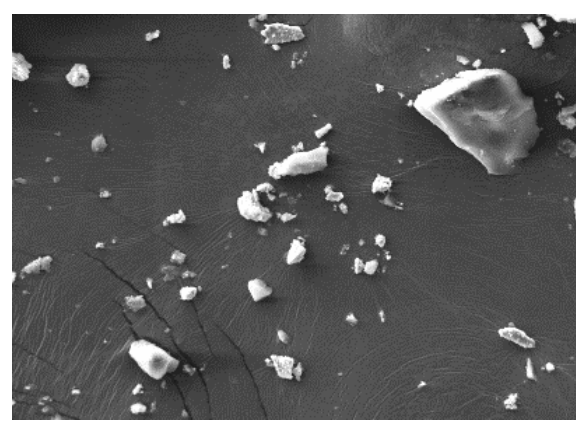

$\mathrm{a}$

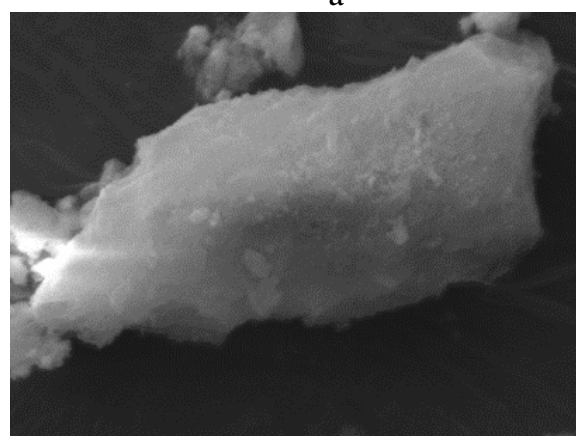

$\mathrm{c}$

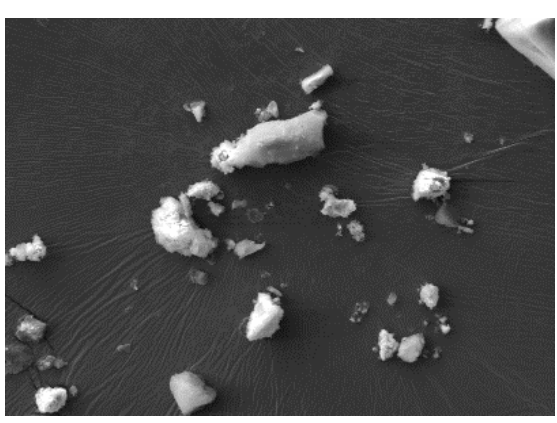

b

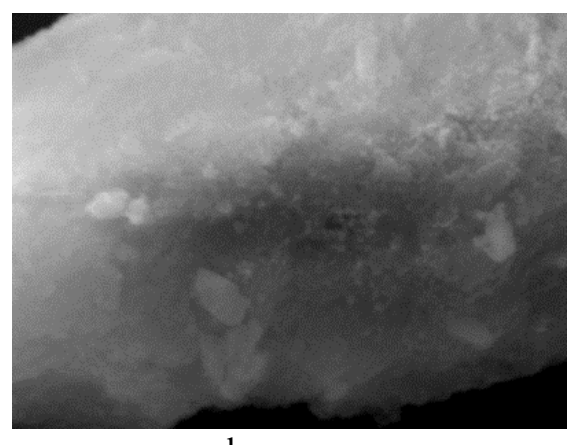

$\mathrm{d}$

Gambar 2. Morfologi dari nanosilika dengan surfaktan CMC menggunakan SEM perbesaran (a) 500x, (b) 1000x, (c) 5000x, dan (d) $10000 x$.

\section{Morfologi Nanosilika}

Gambar 2 menunjukkan morfologi dari nanosilika yang telah dihasilkan. Pada Gambar 2 tersebut terlihat bentuk morfologi nanosilika yang dihasilkan tidak beraturan dan terlihat ada sebagian partikel yang berukuran besar dari ukuran partikel lainnya. Partikel besar tersebut merupakan partikel yang tersusun atas partikel-partikel kecil yang telah mengalami proses aglomerasi. Gambar 2 (a) dan (b) terlihat bahwa distribusi ukuran partikel nanosilika yang dihasilkan cukup merata dengan PDI yang dihasilkan adalah 0,047. Hal ini mengindikasikan terjadinya proses aglomerasi telah terminimalisasi dengan adanya penambahan surfaktan. Gambar 2 (c) dan (d) menunjukkan permukaan dari sampel nanosilika yang terlihat jelas bahwa struktur kristal nanosilika yang dihasilkan teratur. Pernyataan ini dibenarkan oleh Ismayana (2014), bahwa pada proses sintesis nanosilika menggunakan metode ultrasonikasi menghasilkan susunan kristal yang lebih teratur karena metode tersebut dapat menimbulkan panas. Panas yang dihasilkan dapat mendorong susunan kristal nanosilika menjadi lebih teratur.

Informasi tambahan yang didapatkan dari analisis dengan SEM adalah data EDS, yang menunjukkan unsur-unsur yang terdapat dalam sampel serta komposisi sampel berdasarkan unsur tersebut. Hasil yang diperoleh menunjukkan terdapatnya berbagai unsur kimia dalam sampel, meliputi O, Si, C, Na, dan K. Atas dasar keberadaan unsur tersebut, dapat diduga bahwa dalam sampel terdapat berbagai fase meliputi $\mathrm{SiO}_{2}, \mathrm{Na}_{2} \mathrm{O}, \mathrm{K}_{2} \mathrm{O}$, dan $\mathrm{CaO}$.

\section{KESIMPULAN DAN SARAN}

\section{Kesimpulan}

Metode ultrasonikasi untuk sintesis nanosilika yang berasal dari abu ketel limbah industri gula dapat menghasilkan nanosilika dengan derajat kristalinitas yang tinggi. Pemberian surfaktan dapat meningkatkan keseragaman ukuran partikel nanosilika yang dihasilkan, karena dapat menghindari adanya aglomerasi diantara partikel nanosilica. Surfaktan pada sintesis nanosilika akan melindungi pertumbuhan kristal sehingga menghasilkan derajat kristalinitas yang lebih tinggi. Selain itu, penambahan surfaktan juga mampu meningkatkan derajat kristalinitas. Keteraturan pertumbuhan kristal nanosilika dengan adanya penambahan surfaktan akan menurunan ukuran kristal partikel nano yang dihasilkan.

\section{Saran}

Penelitian lanjutan pelu dilakukan dengan memvariasikan waktu ultrasonikasi, meningkatkan konsentrasi surfaktan, serta optimasi penambahan surfaktan yang memiliki viskositas tinggi.

\section{UCAPAN TERIMA KASIH}

Ucapan terima kasih kepada Direktorat Riset dan Pengabdian Masyarakat, Direktorat Jenderal Penguatan Riset dan Pengembangan, Kementerian Riset, Teknologi dan Pendidikan Tinggi yang telah memberikan dana melalui Hibah Kompetensi untuk menjalankan penelitian ini. 


\section{DAFTAR PUSTAKA}

Abdullah M, Virgus Y, Nirmin, Khairurrijal. 2008. Review: Sintesis nanomaterial. Jurnal Nanosain \& NanoTeknologi 1(2):33-57.

Affandi S, Setyawan H, Winardi S, Purwanto A, Balgis R. 2009. A Facile method for production of high purity silica xerogel from bagasse ash. Journal Advanced Powder Technology. $20: 468-472$.

Awizar DA, Othman NK, Jalar A, Daud AR, Rahman IA, Al-hardan NH. 2013. nanosilicate extraction from rice husk ash as green corrosion inhibitor. International Journal Electrochem Science. 8:1759-1769.

Delmifiana B dan Astuti. 2013. Pengaruh sonikasi terhadap struktur dan morfologi nanopartikel magnetik yang disintesis dengan metode kopresipitasi. Jurnal Fisika Unand. 2(3):186189.

Fahyuan HD, Dahlan D, dan Astuti. 2013. Pengaruh konsentrasi CTAB dalam sintesis nanopartikel $\mathrm{TiO}_{2}$ untuk aplikasi sel surya menggunakan metode sol gel. Jurnal Ilmu Fisika. 5 (1) : 16-23.

Gao K. 1993. Polyethylene Glycol as an Embedment for Microscopy and Histochemistry. CRC Press. 1-10.

Geetha D dan Thilagavathi T. 2010. Hydrothermal synthesis of nano $\mathrm{ZnO}$ structures from CTAB. Digest Journal Nanomater Biostruct. 5(1): 297-301.

Gurav JL, Rao AV, Rao AP, Nadargi DY, Bhagat SD. 2009. Physical properties of sodium silicate based silica aerrogel prepared by single step sol-gel process dried at ambient pressure. Alloys and Compounds. 476 : 397402.

Hanafi AS dan Nandang AR. 2010. Studi pengaruh bentuk silika dari abu ampas tebu terhadap kekuatan produk keramik. Jurnal Kimia Indonesia. 5(1):35-38.

Ismayana A. 2014. Perancangan proses cocomposting dan nanoteknologi untuk penanganan limbah padat industri gula [Disertasi]. Bogor (ID) : Institut Pertanian Bogor.

Kurniawan D. 2013. Sintesis nanopartikel serat rami dengan metode ultrasonikasi. [Skripsi]. Bogor (ID) : Institut Pertanian Bogor.

Lestari P, Titi N, Siti H, Djagal W. 2014. Pengembangan teknologi pembuatan biopolimer bernilai ekonomi tinggi dari limbah tanaman jagung (Zea mays) untuk industri makanan. Laporan Penelitian. Yogyakarta : Universitas Gajah Mada.

Lidiniyah. 2011. Peningkatan jumlah nanopartikel kitosan terisi ketoprofen berdasarkan ragam surfaktan dan kondisi ultrasonikasi. [Tesis]. Bogor (ID) : Institut Pertanian Bogor.

Mohanraj VJ dan Chen Y. 2006. Nanoparticles - A Review. Tropical Journal of Pharmaceutical Research. 5(1):561-573.

Pausa Y, Mariana B, dan Yudha A. 2015. Optimasi tingkat kemurnian silika, $\mathrm{SiO}_{2}$, dari abu cangkang sawit berdasarkan konsentrasi pengasaman. Prisma Fisika. 3(1) : 1-4.

Purwati S, Soetopo R, dan Setiawan Y. 2007. Potensi penggunaan abu boiler industri pulp dan kertas sebagai bahan pengkondisi tanah gambut pada areal gambut tanaman industri. Selulosa. 42(1):8-17.

Safitri D. 2012. Sintesis nanopartikel serat kulit rotan dengan metode ultrasonikasi. [Skripsi]. Bogor (ID) : Institut Pertanian Bogor.

Setyawan H, Wibawa G, dan Taufani F. 2007. Pengembangan proses pembuatan silika gel dari abu ketel pabrik gula. Laporan Penelitian Hibah bersaing Dirjen DIKTI Kemendiknas. Surabaya: Institut Teknologi Sepuluh November.

Sembiring S dan Karo-Karo P. 2007. Pengaruh suhu sintering terhadap karakteristik termal dan mikrostruktur silica sekam padi. Jurnal Sain MIPA. Edisi Khusus. 13(3): 233-239.

Siswanto, Hamzah M, Mahendra A, Fausiah. 2012. Perekayasaan nanosilika berbahan baku silika lokal sebagai filler kompon karet rubber air bag peluncur kapal dari galangan. Prosiding. Workshop Insinas Jakarta, 29-30 Nop 2012.

Suka I, Wasinton S, Simon S, Evi T. 2008. Karakteristik silika sekam padi dari provinsi Lampung yang diperoleh dengan metode ekstraksi. MIPA. 37(1) : 47-52.

Tarirai C. 2005. Cross-linked chitosan matrix systems for sustained drug release [Thesis]. Tshwane: Tshwane University of Technology.

Thassu D, Pathak Y, dan Deleers M. 2007. Nanoparticulate Drug-Delivery Systems : an Overview. Di dalam: Thassu D, Pathak Y, Deleers M, editor. Nanoparticulates Drug Delivery Systems. New York: Informa healthcare. Hlm. 1-31.

Thuadaij N dan Nuntiya A. 2008. Preparation of nanosilica powder from rice husk ash by precipitation method. Chiang Mai Journal Science. 35(1) : 206-211.

Tiyaboonchai W. 2003. Chitosan nanoparticles: a promising system for drug delivery. Naresuan University Journal. 11(3):51-66.

Yudhistira AD, Fajar BI, dan Tutuk DK. 2012. Pembuatan asimetrik membran untuk pengolahan air : pengaruh waktu penguapan terhadap kinerja membran. Jurnal Teknologi Kimia dan Industri. 1(1) : 186-193. 